\title{
Preface
}

\section{The Female Athlete}

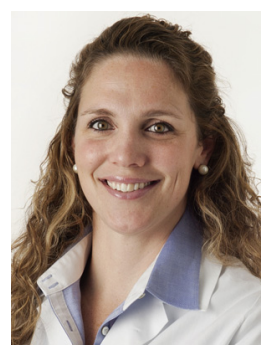

Siobhan M. Statuta, MD, CAQSM

Editor

Women's participation in sport has risen in the last 50 years, and boy, is that an understatement! (pun intended). This is fact, regardless of the level of sport. Consider the marathon of all marathons: Boston. It doesn't matter whether you credit Bobbi Gibb for being the first female finisher of this race in 1966 when she snuck in unofficially without a number, or you recognize Kathrine Switzer who successfully completed the race the following year as a bibbed runner due to a registration error. Both are considered pioneers and were retroactively acknowledged as race champions by the Boston Athletic Association years later. It was finally in 1971 that women were officially permitted to register and run the race. Over the years, the number of female finishers has skyrocketed to an astounding $45 \%$ of registered runners: 13,698 in $2017 !^{1}$ Stories like this are not unique to the running community alone, but are evidenced across sport and level of competition as well. In 1970, there were approximately 16,000 female intercollegiate athletes. By 2016 , this number exceeded $214,000 !^{2}$ In the high school arena, the 2016 National Survey reported girls' athletic participation had reached an all-time high: over 3,324,000. Moreover, this was the 27th consecutive year of increased sport participation by girls in high school. ${ }^{3}$ Girls recreational sports at even younger ages are established as well. Girls have greater access to a wider array of sports and are getting involved at younger ages, and the rise in participant numbers proves this.

Parallel to this upsurge in female athletics, the subspecialty of sports medicine has also evolved. With it now comes the unique challenge of treating these female athletes. Female athletes, though able to play and maneuver similarly to their male counterparts, are indeed different beings. Anatomical and physiological variances place women in a separate category than men, oftentimes placing them at greater risk for injury. It is imperative that the sports medicine clinician be aware of the nuances of the female athlete. By recognizing these distinctions, it allows the sports medicine physician the ability to better counsel the female athlete on nutrition, psychology, physical 
conditioning, the prevention of injuries, and increasing performance. It is our duty, as the medical team, to stay current with the latest evidence, in order to more successfully serve as educator and care provider. This female-focused issue of Clinics in Sports Medicine provides a variety of challenging and dynamic topics with the aim not only to provide a comprehensive review but also to serve as a reference for years to come.

A special thank you to all the contributing authors who took time out of their busy lives to research, create, and contribute such valuable articles to this issue. It has been a true honor to collaborate on this project. Finally, l'd like to especially thank Dr Mark Miller for his mentoring and support throughout the years as well as for providing me this platform to further the knowledge and education of fellow clinicians and professionals alike. Enjoy!

\author{
Siobhan M. Statuta, MD, CAQSM \\ Department of Family Medicine \\ University of Virginia Health System \\ PO Box 800729 \\ Charlottesville, VA 22908-0729, USA \\ E-mail address: \\ SMS5BB@virginia.edu
}

\title{
REFERENCES
}

1. Boston Athletic Association. 2017 Boston marathon statistics. Available at: http:// registration.baa.org/2017/cf/Public/iframe_Statistics.htm. Accessed April 28, 2017.

2. 2015-16 NCAA sports sponsorship and participation rates report. Available at: http://www.ncaapublications.com/productdownloads/PR1516.pdf. Accessed April 28, 2017.

3. 2015-16 High school athletics participation survey. The National Federation of State High School Associations. Available at: http://www.nfhs.org/ParticipationStatistics/ PDF/2015-16_Sports_Participation_Survey.pdf. Accessed April 28, 2017. 